\title{
The Contribution Of Ecological Footprinting To Planning Policy Development: Using The REAP Programme To Evaluate Policies For Sustainable Housing Construction
}

Michael Nye ${ }^{1}$ and Yvonne Rydin ${ }^{2}$

1. Senior Research Associate, Centre for Environmental Risk, University of East Anglia

2. Professor of Planning, Environment and Public Policy, Bartlett School of Planning, University College London

Corresponding author

Yvonne Rydin

Bartlett School of Planning,

University College London,

Wates House,

26 Gordon Street

London WC1H 0QB

Y.Rydin@ucl.ac.uk

Tel. 02076797501

Fax 02076797502

\section{Acknowledgements}

We wish to acknowledge project funding from the HEFCE Higher Education Innovation Fund and also supplementary funds from the Greater London Authority to enable this REAP analysis. We also wish to thank John Barrett of SEI-York for his advice and support. This paper reflects the views of the authors and not those of either the GLA or SEI-York. 


\title{
The Contribution Of Ecological Footprinting To Planning Policy Development: Using The REAP Programme To Evaluate Policies For Sustainable Housing Construction
}

\begin{abstract}
The complexity of the sustainable development policy goal is such that policy-makers are searching for tools to enable them to evaluate and develop policy directions. To date, Ecological Footprinting has been used mainly for raising awareness of environmental impacts but it also has considerable potential as a policy tool, enabling policy-makers in their strategic work. The paper presents an application of a specific Ecological Footprinting development, the REAP tool, to a current policy issue, the promotion of sustainable construction. Using the Greater London Authority as a case study, it considers the strengths and weaknesses of this approach and how it can contribute to policy development.
\end{abstract}

\section{Introduction}

The significance of the broad sustainable development agenda has been growing over the past two decades. With the maturing of this agenda, more attention is now being paid to how specific sectors and activities can adapt to pursue more sustainable paths. Sustainable construction is one such area. Just as sustainable development is itself a term capable of multiple definitions, sustainable construction is not a neatly packaged term. It is used to cover techniques of construction alongside matters of development design, and even urban design. It can encompass concerns with designing out crime and ensuring physical accessibility alongside more strictly environmental concerns. And the environmental dimensions of sustainable construction can range from protecting trees on site and creating new habitats, to promoting water conservation and using recycled materials, and to enhancing the energy efficiency of buildings and allowing for renewable modes of energy generation.

The lack of a consistent and concise definition has not constrained the development of policy initiatives on sustainable construction both at the industrial sector level and within urban planning. Our research focuses on the decisions that can be made within the planning system for promoting sustainability of new building. It presents the results of a scenario-based, Ecological Footprinting study of housing constructions standards aimed at sustainability in London. In addition to highlighting which planning standards have the greatest impact on the sustainability of a new home, this paper provides a critical evaluation of the usefulness of Ecological Footprinting as a planning tool.

\section{Ecological Footprints: definitions and applications}

An 'Ecological Footprint' (EF) is a measurement of the area of land and water needed to support human consumption, production and waste activities at current, or projected levels (Wackernagel and Rees, 1996). In its most basic form, it is a simple accounting tool for measuring the load of human consumption in terms of global impact (Chambers, et al., 2000). There are six primary land types that are used to calculate an EF. These are bio-productive land (cropland, pasture and forest), bio-productive sea, energy land (forest and sea area 
required for the sequestration of $\mathrm{CO} 2$ emissions, and built land (infrastructure and roads) ${ }^{1}$ (Wackernagel and Rees, 1996). The power of the EF is that it converts typically complex resource use patterns into a single aggregate number (Constanza, 2000), thereby providing a readily understandable and comparable 'snapshot' (Reese, 2000, 373) of the impacts of consumptive practices and the extent to which environmental limits are being exceeded. In this context, EF analysis has been applied to calculating the Footprint of London, (BFF, 2002, WSP, 2003) and to sustainable urban form (Holden, 2004) and housing (Wiedmann et al., 2003; Ravetz et al., 2006).

Despite the potential for EF analysis to deliver a spatial indicator of sustainability, there are certain limitations to the usefulness of compound, or aggregate land data EF calculations as an indicator of sustainable activity, particularly when applied on a local or regional level. These include a general lack of good quality resource use and materials flow data for the calculation of regional or local Footprints, an insufficient ability to account for indirect materials flows, especially in the tertiary sector, and the more general idea that EF analysis does not accurately reflect the impacts of consumption activities (Weidmann et al., 2005; Moffatt et al., 2001). This latter shortcoming reflects the globally-aggregate nature of the EF and the oversimplification of complex relationships implicit in such aggregate indicators. Aggregation is at once the strong point of the EF, in terms of its usefulness as a snapshot of sustainability and sustainable limits, and a potential shortcoming because the every-day activities of human beings are decoupled from the aggregated ecological impacts of their actions (Wiedmann et al. 2005). it as been suggested that practical EF analysis may need to be combined with more detailed methodological approaches such as input-output accounting or natural resource accounting (Moffatt, 2000; McGregor et al., 2004; Moffatt, et al., 2005).

An alternative calculation for EF scores, termed the 'component' method, has been derived in response to the need for regionalised and local Footprint calculations, and more practical Footprint applications. The component-based EF method focuses on the Footprint effects of consumption and consumptive activities rather than on the appropriation of materials from the ecosphere (Barrett, 2001). It focuses on the components of resource appropriation, in terms of water, energy, transport and waste. Such a focus on the human activities behind resource consumption retains the original materials and resource flow ideas behind Ecological Footprint analysis, but presents the results in terms of real world activities that are more applicable to policy analysis and indicator applications (Barrett, 2001, Wiedmann, et al., 2005). Indeed, Simmons, (2000), asserts that this 'bottom up approach' can be used to examine the impact of different consumptive patterns, lifestyles, or practices down to the level of the individual consumer (2000: 379).

An important practical development from the component-based Footprint method is REAP, (Resource and Energy Analysis Programme) which was designed by the UK Office of the Stockholm Environment Institute (SEI; www.sei.se/reap). REAP uses an environmental extended input-output analysis (Miller and Blair, 1985) framework to assign EF scores to consumption activities in final demand categories. In doing so, it creates a linkage between National Footprint Accounts ((NFA) data (GFN, 2004), and monetary, supply and use data for consumption based on PRODCOM data (Wiedmann et al., 2005). ${ }^{2}$ This supply and use format takes into account the "mutual interrelationships among economic sectors and allows

\footnotetext{
${ }^{1}$ For an introduction to the footprint concept see: Wackernagel, M, and W Rees, 1996,. Our Ecological Footprint: Reducing human impact on the earth. (New Society Publishers. Canada).

${ }^{2}$ For a detailed discussion of NFA calculation methods in the context of component-based footprint analysis. see also Wackernagel et al., 2005, National Footprint and Biocapacity Accounts 2005: The underlying calculation method. Oakland: Global Footprint Network http://www.globalfootprint.org
} 
affiliations for material, energy and waste flows to be accurately assigned to final consumption categories" in terms of Ecological Footprints (Wiedmann and Barrett, 2005: 5). ${ }^{3}$

The key benefit of REAP EF analysis is that it allows the breakdown of Ecological Footprints from consumption at the regional or local level. This allows for EF scores to be employed as a truly 'bottom up' indicator of sustainability at much smaller scales, even though the overall impact of consumption is still measured on a global scale. The WWF states that "REAP will enable decision maker to generate different policy scenarios to integrate 'One Planet Living' into strategy development" (WWF 2005: 3). Recent applications of REAP by SEI at the regional and local level include an investigation of the Ecological Footprint of Wales that features a micro-lifestyle assessment exercise (WWF, 2005) and a Footprint analysis of the Footprint for different housing types (Wiedmann et al. 2003).

For this research, the REAP tool and underlying spreadsheet calculations have been applied to a scenario-based analysis of planning standards aimed at sustainable housing construction in London. Such an evaluation is important because of the emphasis on sustainable construction in recent London planning and development guidance, and, more pertinently, because of the potential impact of the construction industry on the wider Footprint of a London. The construction industry is the largest single user of resources in the UK, consuming 420 million tonnes of materials annually (Smith, et al., 2002). In London, 27.8 million tonnes of construction materials are consumed each year (BFF, 2002). Bringing these figures down to the housing scale, we find that a 'typical' London house requires 121 tonnes of materials (Wiedmann et al., 2003). In addition to materials use, recent studies by SEI reveal that decisions at the planning and level can have an important impact on the energy use patterns of housing residents (Wiedmann et al., 2003). Findings such as these suggest that housing construction can have both an immediate impact on the EF of a community in terms of the materials and energy used to construct a home, and a longer, lifecycle impact attributed to the energy and resource use efficiencies of a building.

\section{REAP and planning for sustainability in London}

This paper presents the results and critical analysis of a REAP scenario-based analysis of standards aimed at sustainable housing construction in London. The wider framework for these scenarios is laid out in the 2004 London Plan. The London Plan is a strategic planning document that sets out 'an integrated social, economic and environmental framework for the future development of London (GLA, 2004: 8). It covers a diverse array of planning and development issues such as transport, community building, working in London, protection of natural resources, and provision of new housing within the 32 London boroughs (2004).

Subsequent to the publication of the London plan, several Supplementary Planning Guidance (SPG), documents have been produced that concentrate on specific aspects of the broader London Plan. The 2005 draft SPG for Sustainable Design and Construction forms the primary platform for scenario building in this research. ${ }^{4}$ This 81-page document outlines a

\footnotetext{
${ }^{3}$ For a detailed account of the input/output methods used in REAP see:

Wiedmann, T, and Barrett, J, 2004, Development of Physical Accounts for the UK and Evaluating Policy

Scenarios. REAP Report No.1.

Wiedmann, T, and Barrett, J, 2005, The Use of Input-Output Analysis in REAP to allocate Ecological

Footprints and Material Flows to Final Consumption Categories. REAP Report No.2.

Both available at: www.regionalsustainability.org.
}

${ }^{4}$ There is also an SPG for Housing Provision which was not evaluated directly, but which did inform the overall direction of this study. The final version of the SPG on sustainable design and construction was issued in May 2006. 
set of 'essential' (required) and 'preferred' standards for construction in London's commercial, public and housing sectors. These standards cover sustainable construction activities and practices in such areas as reuse of buildings, reducing air pollution, enhancing the natural environment, building green, and transporting materials (GLA, 2005b). A listing of the draft SPG standards evaluated in this paper, and the ways in which they were operationalised for scenario testing, is provided in Nye and Rydin (2006). ${ }^{5}$ These standards were chosen for discussion in this paper because they represent a good cross section of the types of sustainable practices that can be influenced at the planning level, and because they demonstrate the strengths and weaknesses of using component Footprints as an indicator of sustainability.

Table 1 Standards evaluated in this paper

\begin{tabular}{|c|c|c|}
\hline & DRAFT SPG STANDARD(S) & STANDARD USED IN SCENARIOS \\
\hline Recycled materials & $\begin{array}{c}\begin{array}{c}\text { Minimise demolition waste and specificy use } \\
\text { of recycled materials }\end{array} \\
\end{array}$ & $25-35 \%$ use of recycled materials in new build. \\
\hline $\begin{array}{c}\text { Embodied energy of } \\
\text { materials }\end{array}$ & $\begin{array}{c}\text { Avoid high embodied energy materials where } \\
\text { possible }\end{array}$ & $\begin{array}{l}\text { Avoid high embodied energy materials where building } \\
\text { regulations allow and where suitable substitutes exist. }\end{array}$ \\
\hline $\begin{array}{l}\text { Community heating } \\
\text { and CHP }\end{array}$ & $\begin{array}{l}\text { Design for community heating and CHP for } \\
\text { large developments }\end{array}$ & $\begin{array}{l}\text { Installation of community heating and combined heat and } \\
\text { power in all large developments }\end{array}$ \\
\hline Water savings & $\begin{array}{c}\text { Inclusion of water saving devices in all new } \\
\text { build }\end{array}$ & $\begin{array}{l}\text { Achieve average water use of } 40 \mathrm{~m} 3 \text { per bedspace per year } \\
\text { in all new build. }\end{array}$ \\
\hline $\begin{array}{l}\text { Household waste } \\
\text { recycling }\end{array}$ & $\begin{array}{l}\text { Provide facilities for recycling household } \\
\text { waste }\end{array}$ & $\begin{array}{c}25-60 \% \text { Recycling of household paper, card, glass and } \\
\text { metal waste }\end{array}$ \\
\hline
\end{tabular}

The scenario-building process involved two distinct stages. Initially, a benchmark, or current practice scenario, was created that reflected levels of current achievement for each of the evaluated standards. Following the benchmarking exercise, 'required' and 'preferred' housing construction scenarios were created based on the standards and strategic direction in the draft SPG and the London Plan. The basic steps involved in this process are outlined below:

1. Determine the Footprint category and appropriate REAP scenarios manager for the standard in question.

2. Determine the scale(s) of practice on which the standard will be applied.

3. Determine the levels of the standard needed to meet the strategic direction of the standard as outlined in the draft SPG.

This basic formula was adapted to construct the scenarios for each of the standards evaluated in this paper. For instance, in order to evaluate the effect of using recycled aggregates in London housing construction, it was necessary to first identify a baseline value for use of aggregates in new housing construction. This baseline calculation was then compared to the number of new London from 2005-2016 houses for which aggregates or recycled aggregates will be required, and the current levels of use for recycled aggregates in new housing construction. Finally, test scenario values (in this case a 10\% and $20 \%$ increase in the use of recycled aggregates) were selected. These values represent an increase in the use of recycled aggregates beyond current use levels and 'business as usual' demand projections.

\footnotetext{
5 This paper presents the results for a selection of standards in several areas. In total, 16 preferred and required standards were evaluated in the broader programme of research upon which this paper is based.
} 
This process of operationalising policy parameters into 'real world' scenarios for what could be achieved in terms of sustainable construction practices often required the researchers to choose between specific designs or specific product options. Where the draft SPG did not require a specific design option or product, the choice of design and product options was guided with reference to the data discussed in the remainder of this section and personal interviews with planning, design, and conservation experts. ${ }^{6}$

\section{Baseline Footprint values}

The analysis evaluates the reduction in Ecological Footprint due to the implementation of a planning standard against a current baseline Footprint value. The baseline Footprint values used in this report are displayed in Table 2. Table 2 also displays the Footprint categories, or components that make up the portion of the London Footprint evaluated here.

Table 2 Baseline Footprint values for this report

\begin{tabular}{|c|c|}
\hline EF COMPONENT & gha/pers \\
\hline Infrastructure & 0.1151 \\
\hline Energy & 0.3830 \\
\hline Water & 0.00195 \\
\hline Waste & 0.6490 \\
\hline Total & $\mathbf{1 . 1 4 9 1}$ \\
\hline
\end{tabular}

Calculated from SEI data (2001)

The baseline EF scores in Table 2 represent the benchmark values against which scenario standards were evaluated in this paper. It shows those portions of the larger, 'business as usual' London Footprint that were relevant to our scenarios. The specific methods for calculating each of these baseline Footprint values will be discussed in more detail in corresponding sections.

A total Footprint of $1.1491 \mathrm{gha} / \mathrm{cap}$ is far below the $6.63 \mathrm{gha} / \mathrm{cap}$ Footprint of the average Londoner as calculated in the City Limits Footprinting exercise of London (BFF, 2002) and the $5.8 \mathrm{gha}$ /cap Footprint calculated by WSP (2003). ${ }^{7}$ This is because not all Footprint components were relevant to our scenarios, and because only certain elements of the categories listed above were evaluated ${ }^{\mathbf{}}$. Table 2 also shows that REAP Footprint calculations are presented as per-capita 'global hectares' (gha/cap) for a given population. The use of a per capita Footprint calculation allows Footprint scores to be aggregated across several parameters, or where scenario overlaps occur.

\footnotetext{
${ }^{6}$ The draft BRE/WWF checklist for sustainable design was a checklist aimed at planners that suggested rankings of objectives for achieving the policy goals in the draft SPG. It was circulated for comment in Late 2005, but never fully developed.

${ }^{7}$ Footprint calculations differ between the two studies because they do not cover the same elements of consumption.

${ }^{8}$ For instance, the transport EF component does not include air travel, the energy EF component only includes electricity and gas, no evaluation of the 'food' component was performed, and the materials (infrastructure) component only relates to materials used in construction of a new house.
} 


\section{Building Materials Standards: recycled and low embodied energy building materials}

Materials and infrastructure standards were evaluated with the REAP infrastructure scenario manager. The infrastructure scenario manager allows the user to adjust materials quantities $(\mathrm{Kg})$, transport distances $(\mathrm{Km})$, and embodied energies $\mathrm{CO}_{2}(\mathrm{MJ}$ and $\mathrm{kg}$ ) for a range of materials in both a typical 'stock house' and a 'new' (built after 2000) house. Baseline materials weights, transport values, and embodied energy of materials for typical UK houses are included within the REAP scenario manager. A listing of materials evaluated in this research for a 'typical new' house is provided in Table 3 below:

Table 3 Materials used in housing construction: Weights and transport distances

\begin{tabular}{|c|c|c|}
\hline MATERIALS & COMPOSITION (KG) & TRANSPORT (KM) \\
\hline Spoil/fill & 26400 & 10 \\
\hline Concrete (mass/slab) & 28000 & 77 \\
\hline Concrete (hollowcore) & 0 & 77 \\
\hline Hardcore & 11600 & 77 \\
\hline Sand & 960 & 40 \\
\hline Blocks (light) & 9100 & 77 \\
\hline Bricks & 15840 & 152 \\
\hline Mortar & 9000 & 77 \\
\hline Mineral wool insulation & 280 & 152 \\
\hline Polyurethene ins. & 470 & 152 \\
\hline Steel & 580 & 139 \\
\hline Aluminium & 250 & 104 \\
\hline Windows/doors aluminium & 0 & 104 \\
\hline Windows/doors uPVC & 1500 & 152 \\
\hline Windows/doors timber & 500 & 233 \\
\hline Plasterboard & 1350 & 152 \\
\hline Plaster & 3000 & 152 \\
\hline Paint & 75 & 152 \\
\hline Glass & 720 & 152 \\
\hline Timber & 2900 & 233 \\
\hline Rein. beams/lintels & 940 & 77 \\
\hline Linoleum & 2 & 5000 \\
\hline Ceramic tile & 210 & 152 \\
\hline Membranes & 1200 & 152 \\
\hline Roofing tiles & 2400 & 152 \\
\hline TOTAL & 117,277 & \\
\hline
\end{tabular}

Source: Wiedmann et al, 2003.

These materials weights, and the energy used to create and transport these materials are combined in the REAP infrastructure scenario manager to create a component-based materials Footprint for a new house. Table 4 displays the components of the materials EF for a new build London house as calculated with the baseline values included in REAP. 
Table 4 Materials EF for a new house

\begin{tabular}{|l|r|}
\hline $\begin{array}{l}\text { MATERIALS } \\
\text { COMPONENTS }\end{array}$ & EF \\
\hline & [gha/pers] \\
\hline Embodied Energy EF & 0.0687 \\
\hline Transport GWP EF & 0.0099 \\
\hline Land (Materials) EF & 0.0364 \\
\hline Total EF/cap & 0.1151 \\
\hline
\end{tabular}

The data in Table 4 indicate that the Ecological Footprint for a typical new build London home is .1151gha/cap. These data were used as baseline values for the evaluation of materials standards for new housing construction in London.

\section{Recycling demolition wastes and specifying the reuse of materials}

In section 2.7.2, the draft SPG calls for developers and planners to

"Minimise, reuse and recycle demolition waste" and "specify use of reused or
recycled construction materials"

In this research, these two required standards have been evaluated in terms of reuse and recycling of construction materials. In the UK, 295,450 tonnes of primary materials are used by the construction industry each year, including approximately 43,000 tonnes of recycled building materials (Smith et al., 2002). This figure represents about $15 \%$ of total primary materials use. Assuming that overall demand for recycled materials would increase in proportion to demand for recycled aggregate material (at 1\% per year (AggRegain, 2006)), a recycled materials use rate of $25 \%$ was initially evaluated with the REAP tool. As a further exercise in evaluating the ecological potential of this standard, a Footprint for recycled material use rate of $35 \%$ was also calculated with REAP.

In order to test this scenario, embodied energy and $\mathrm{CO} 2$ levels of directly re-usable materials used in the construction of a new house were decreased by 10 and $20 \%$. Whereas there are other building products that could be created from recycled materials, these have not been evaluated in this research due to the difficulty of accounting for the embodied energy of reconstituted materials, and the materials mix involved such products. The following materials were evaluated as directly reusable products: doors/windows (UPVC and timber), blocks, bricks, steel, beams/lintels, timber, and roofing tiles. Materials weights for each of these products were not changed, nor were transport values. It was assumed that recycled materials must still be transported, and that the total mass of materials required would remain unchanged. Baseline energy and $\mathrm{CO} 2$ values for each material (without the evaluated 10$20 \%$ reduction in these values) are displayed in Table 5 below. 
Table 5 Embodied CO2 - Recyclable building materials

\begin{tabular}{|c|c|c|}
\hline MATERIAL & $\begin{array}{c}\text { EMBODIED ENERGY } \\
\text { (MJ/KG) }\end{array}$ & $\begin{array}{c}\text { EMBODIED } \\
\text { CO2 (KG) }\end{array}$ \\
\hline Blocks (medium) & 0.8850 & 0.00002 \\
\hline Bricks & 2.9000 & 0.0001 \\
\hline Steel & 30.1370 & 0.0006 \\
\hline Windows/doors uPVC & 53.8175 & 0.0010 \\
\hline Windows/doors timber & 26.8500 & 0.0005 \\
\hline Timber & 27.4727 & 0.0005 \\
\hline Rein. beams/lintels & 4.1837 & 0.0001 \\
\hline Roofing tiles & 2.9000 & 0.0001 \\
\hline
\end{tabular}

Calculated from SEI data

Reducing the embodied energy and $\mathrm{CO} 2$ components for each of these materials by 10 and $20 \%$ yields the following adjustments in the materials EF for a new home.

Table 6 Materials EF for new homes with 25\% recycled materials

\begin{tabular}{|l|r|}
\hline $\begin{array}{l}\text { MATERIALS } \\
\text { COMPONENTS }\end{array}$ & EF \\
\hline & {$[\mathrm{gha} /$ pers] } \\
\hline Embodied Energy EF & 0.0665 \\
\hline Transport GWP EF & 0.0100 \\
\hline Land (Materials) EF & 0.0365 \\
\hline Total EF/cap & 0.1129 \\
\hline
\end{tabular}

Table 7 Materials EF for new homes with 35\% recycled materials

\begin{tabular}{|l|r|}
\hline MATERIALS & EF \\
COMPONENTS & [gha/pers] \\
\hline Embodied Energy EF & 0.0621 \\
\hline Transport GWP EF & 0.0100 \\
\hline Land (Materials) EF & 0.0365 \\
\hline Total EF/cap & 0.1085 \\
\hline
\end{tabular}

Comparing the data in Tables 6 and 7, it appears that increasing the use of recycled materials from $25-35 \%$ will lead to a decrease of .0044gha/cap in the materials EF of a new build house. These Footprint scores represent total savings over new build without recycled materials of .0022, and .0066gha/cap as illustrated in Figure 1. 
Figure 1 EF savings: Use of recycled materials (Gha/cap)

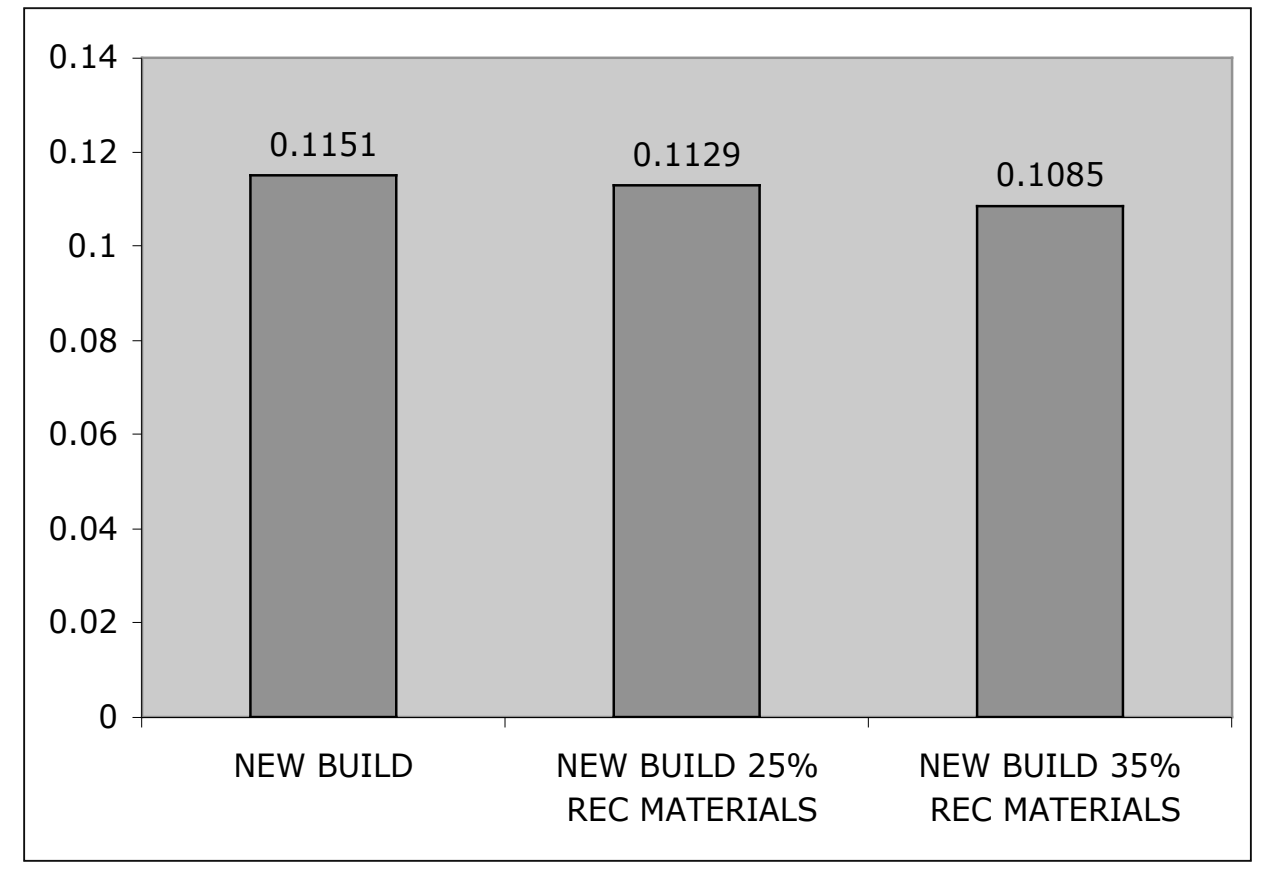

The embodied energy of new materials

In section 2.3.3, the draft SPG calls for

No material of a high-embodied energy to used instead of a material of low embodied energy (as defined by the Green Housing Guide Supplement to the Eco-Homes Environmental Rating Method) (unless a good reason exists)

This preferred standard has been evaluated using the building materials for a typical new house that are listed in Table 3 (materials weights typical house) and the embodied energy data that is included in REAP for these materials.' Table 8 displays a listing of materials for building a typical new home, a list of the embodied energy of these materials, and the differences in materials weights that occur as a result of avoiding high mass materials. Tested materials weights for this standard were taken primarily from BedZed materials values. The weight of timber doors is taken from BRE EcoHomes 'Excellent' materials weights. Materials in bold type represent high-embodied energy materials. Materials weights that have changed are highlighted in grey. In this research, a high-embodied energy material is defined as one that is more than one standard deviation from the inter-quartile mean of the embodied energy values given in Table 8 .

\footnotetext{
${ }^{9}$ The BRE Green Housing Guide Supplement was used only as a guide to what might be considered 'high energy' materials.
} 
Table 8 Embodied energy of materials and values used in scenarios

\begin{tabular}{|c|c|c|c|c|}
\hline MATERIAL & $\begin{array}{c}\text { EMBODIED ENERGY } \\
(\mathrm{MJ} / \mathrm{KG})\end{array}$ & $\begin{array}{c}\text { TYPICAL WEIGHT } \\
\text { (KG) }\end{array}$ & $\begin{array}{c}\text { SCENARIO } \\
\text { WEIGHT (KG) }\end{array}$ & $\%$ CHANGE \\
\hline Spoil/fill & 0.0893 & 26400 & 26400 & \\
\hline Concrete & 0.6423 & 28000 & 28000 & \\
\hline Concrete (hollowcore) & 3.5000 & 0 & 0 & \\
\hline Hardcore & 0.0893 & 11600 & 11600 & \\
\hline Sand & 0.0798 & 960 & 960 & \\
\hline Blocks (light) & 0.8550 & 9100 & 9100 & \\
\hline Bricks & 2.9000 & 15840 & 15840 & \\
\hline Mortar & 2.2450 & 9000 & 9000 & \\
\hline Mineral wool ins. & 18.4000 & 280 & 280 & \\
\hline Polyurethane ins. & 82.3333 & 470 & 470 & \\
\hline Steel & 30.1371 & 580 & 580 & \\
\hline Aluminium & 179.6000 & 250 & 65 & -74 \\
\hline Windows/doors (aluminum) & 218.0000 & $\mathbf{0}$ & $\mathbf{0}$ & \\
\hline Windows/doors (upvc) & 53.8175 & 1500 & $\mathbf{0}$ & -100 \\
\hline Windows/doors timber & 26.8500 & 500 & 1000 & 100 \\
\hline Plasterboard & 5.7333 & 1350 & 1350 & \\
\hline Plaster & 2.4467 & 3000 & 3000 & \\
\hline Paint & 42.2250 & 75 & 75 & \\
\hline Glass & 16.1950 & 720 & 720 & \\
\hline Timber & 27.4727 & 2900 & 3500 & 20 \\
\hline Rein. Beams/lintels & 4.1837 & 940 & 940 & \\
\hline Linoleum & 70.9473 & 2 & 2 & \\
\hline Ceramic tile & 2.9000 & 210 & 210 & \\
\hline Membranes & 68.4242 & 1200 & 1200 & \\
\hline Roofing tile & 2.9000 & 2400 & 2400 & \\
\hline
\end{tabular}

Source: SEI, BedZed, and BRE data.

The reader will note that the scenario weight values for linoleum, membranes, and paint remain the same as those for a typical new home even though these are high-energy materials. These materials weights are the same as those in BedZed and BRE EcoHomes 'excellent'-rated homes. No suitable substitute for these materials was included in the REAP programme. The weights for insulation materials also remain unchanged in order to comply with Part L1 of the 2000 Building Regulations (see ODPM, 2000). The decreased use of UPVC windows and doors has been offset by an increase in windows and doors made of timber using the BRE EcoHomes 'excellent' materials weights for these products. ${ }^{10}$ The decreased use of aluminium is offset by an increase in timber, which is also taken from BedZed values.

Decreasing the use of high embodied energy materials in new build in this manner yields the following change in the materials EF for a new house:

\footnotetext{
${ }^{10}$ The ECO Homes excellent value was chosen because it reflects a shift from UPVC to timber, whereas the BEDzed home also uses some aluminium doors and windows, which are not typical of a new build UK house.
} 
Table 9 Materials EF for new homes with low embodied energy

\begin{tabular}{|l|r|}
\hline $\begin{array}{l}\text { MATERIALS } \\
\text { COMPONENTS }\end{array}$ & EF \\
\hline & [gha/pers] \\
\hline Embodied Energy EF & 0.0571 \\
\hline Transport GWP EF & 0.0100 \\
\hline Land (Materials) EF & 0.0482 \\
\hline Total EF/cap & 0.1154 \\
\hline
\end{tabular}

The data in Table 9 indicate that the materials EF which results from avoiding high embodied energy materials is $.1154 \mathrm{gha} / \mathrm{cap}$. This represents an increase of .003gha/cap over a typical new build house as indicated in Table 2. This finding highlights an important facet of the REAP approach, which takes into account transport distances as well as materials weights and the embodied energy of those materials. The higher EF score for avoiding high embodied energy materials reflects the increased use of timber in the place of aluminium, which has a higher transport value $(233 \mathrm{~km})$ than aluminium (as displayed in Table 3 ) and the increased land take (materials component) that results from using larger amounts of timber. These component differences are displayed in Figure 2.

Figure 2 Component EF breakdown: New build vs. new build with low embodied energy materials (Gha/cap)

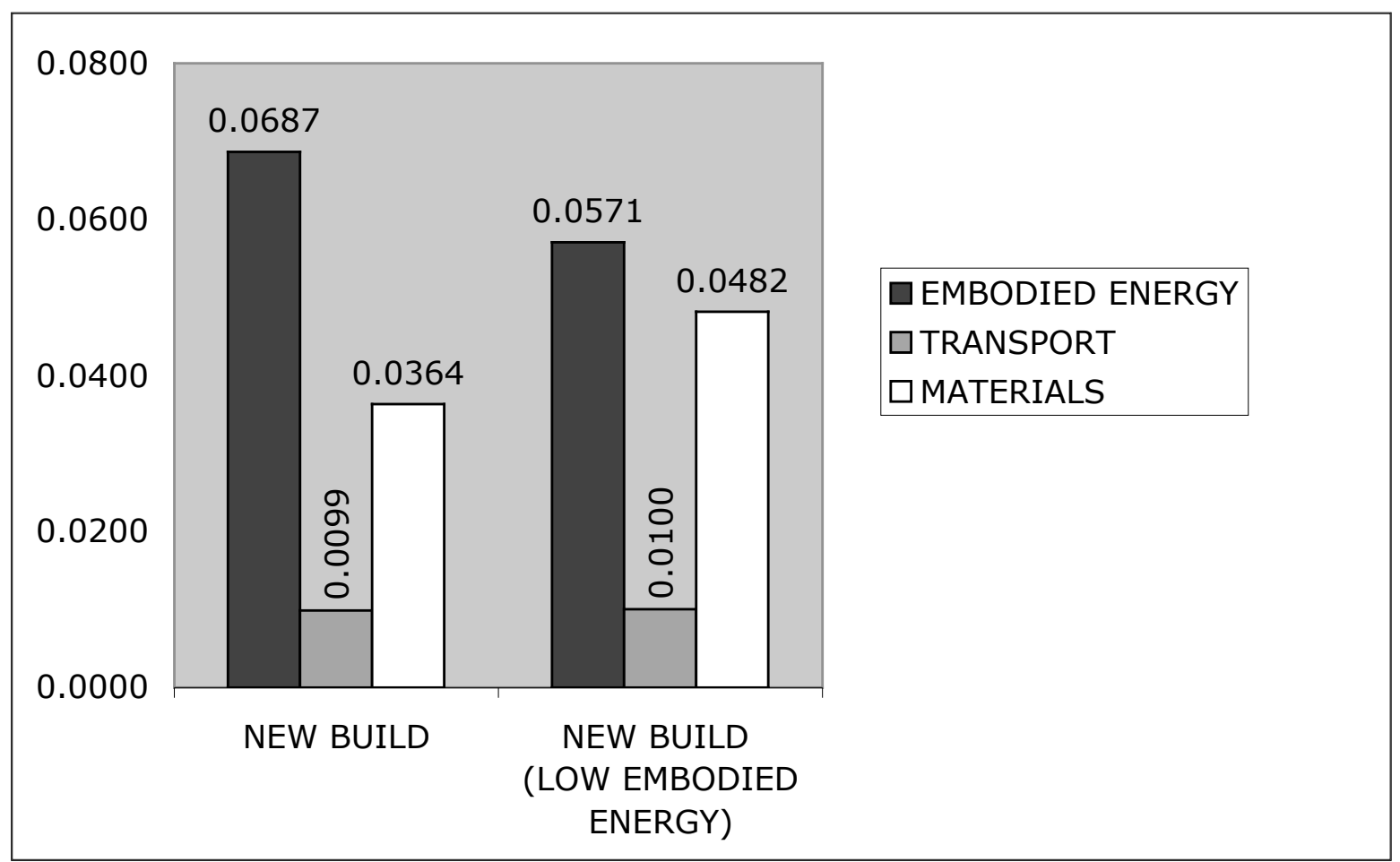

In light of the data in Figure 3 and Table 9, we can conclude that substituting a high transport material for a high-embodied energy material may create an adverse impact on the EF of a new home. This finding highlights the importance of considering transport energies as well as manufacturing energies when defining what is a high-embodied energy material or when creating planning standards. Of course this finding does not take into account that timber is a renewable resource, which is also an important component of sustainability in many contexts. EF analysis is not particularly sensitive to resource supply and security issues, as will be discussed. It is also important to note that the EF differences between the two houses in 
Figure 2 are quite small, a point that might be significant in the context of having to use national as opposed to London-specific data on the distances materials travelled. The practical conclusions from this scenario are that substituting a high-embodied material for a high transport-dependent material will have little net effect on the EF of a home. However, this equivalence of effect in EF terms hides the renewability and supply differences associated with the use of timber versus aluminium products. Therefore, an EF analysis does not necessarily provide a complete comparison of the sustainability of these design options but rather an issue for further investigation.

\section{Energy standards: community heating and community combined heat and power.}

Draft SPG standards oriented towards reducing household energy use were evaluated with the REAP energy scenario manager. The energy scenario manager allows the user to adjust levels of residential energy for space heating, hot water, cooking, and lights and appliances. Only natural gas and electricity use have been evaluated and adjusted in the energy scenario presented in this paper. Data for overall London household electricity and natural gas use were taken from 2005 DTI statistics (DTI, 2005). These data were then broken into proportionate end use categories for London using 2003 DTI figures for nationwide domestic energy consumption by end use (DTI, 2003). Typical electricity and gas energy use levels for a new London home" ${ }^{11}$, are displayed in Table 10 below. These data form the baseline values for the comparison of community and combined heat and power standards that follows.

Table 10 Domestic energy by end use

\begin{tabular}{|c|c|c|}
\hline END USE & GAS & ELECTRICITY \\
\hline & $(\mathrm{kWh} / \mathrm{cap})$ & $(\mathrm{kWh} / \mathrm{cap})$ \\
\hline Space heating & 2,292 & 108 \\
\hline Hot water & 1,646 & 216 \\
\hline Cooking & 174 & 109 \\
\hline Lights/appliances & - & 1,152 \\
\hline Total & 4,112 & 1,585 \\
\hline
\end{tabular}

Calculated from: DTI Domestic Energy Consumption by End Use statistics.

In section 2.2.3 the draft SPG calls for

Minimum: Major commercial and residential developments to demonstrate that consideration has been given to the following ranking method for heating and cooling systems: Passive design Solar water heating; then combined heat and power (if possible regeneration), preferably fuelled by renewables; then community heating; then heat pumps; then gas condensing boilers; and then gas central heating.

Preferred: All developments to demonstrate that consideration has been given to the following ranking method for heating systems, and should incorporate the highest feasible of the following options: solar water heating; then possible regeneration,

\footnotetext{
${ }^{11}$ In this case, 'new' means a home which was built after 2000, and which includes the higher insulation levels mandated in part L1 of the 2000 building regulations (see ODPM, 2000). Wiedmann et al. (2003) indicate that these regulations create a $44 \%$ decrease in the energy EF for a 'new 2000' home as compared to a pre-2000, or stock, house.
} 
preferably fuelled by renewables; then community heating. New developments should always be connected to existing community heating networks where feasible

The Footprint impacts of designing large-scale (over 10 units) housing developments to include community heating and community combined heat and power are analysed and discussed in this paper. Proportions for large and small sites as part of projected new build for London from 2005-2016 were taken from the 2004 GLA housing capacity study (GLA, 2005a). It is assumed that large sites will contribute approximately $60 \%(164,862$ new homes) of new build from 2005-2016, and that small sites and other conversions/vacancies will contribute the remaining 40\% (109,908 new homes). Assumed energy savings and energy use adjustments are based on scenarios in which community heating or combined community heating and power provided by a natural gas fired Stirling engine.

For the minimum standard, a savings of $25 \%$ in natural gas use for space heating (once $\mathrm{CH}$ engine/boiler fuel is taken into account) was evaluated. These savings are consistent with projected savings in recent planning guidance for installation of a Stirling engine installed against heat supplied by a fossil fuel mix and an older boiler. (CHPA, 2005, Carbon Trust, 2005). Because using generated electricity on site requires increased investment from renting electric lines and infrastructure or installing new lines locally, the minimum standard has been evaluated as a shift to $\mathrm{CH}$ rather than CCHP. It is assumed that any electricity generated will be unused or put back into the grid with minimal EF effects. ${ }^{12}$ For the preferred standard, the same savings of $25 \%$ for natural gas use for space heating was evaluated, with generated electricity also taken into account as used on site. ${ }^{13}$ Therefore, the preferred scenario also contains an EF evaluation for large site electricity use reduced $100 \%$ (or to 0 ). The results of this analysis are displayed below.

\footnotetext{
${ }^{12}$ In order to avoid 'double counting' between the preferred and minimum scenarios, electric space heating was not evaluate. It is assumed that all new build will operate with gas heating.

${ }^{13}$ We have assumed a load factor of 1 , meaning that all the all generated electricity is used on- site, and that the CHP engine can supply all of the electricity demands of the development year round. This is a best-case assumption. CHP often requires significant boosts from the local grid.
} 
Figure 3. Raw savings: Large developments - community heating and combined heat and power (Gha/cap)

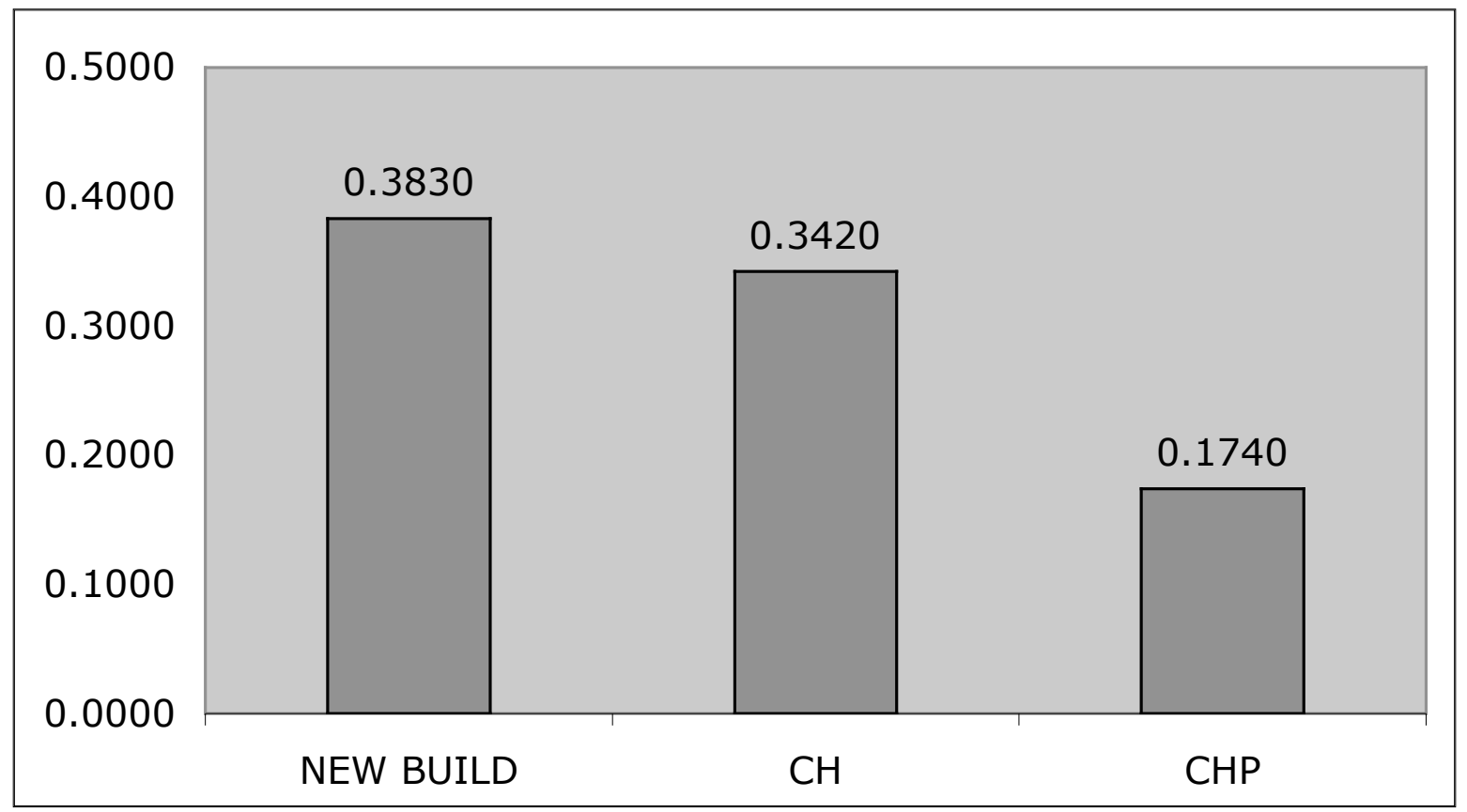

The raw Footprint savings for new build with community heating and combined heat and power are more significant than those for new build with gas condensing boilers and solar water heating. Community heating by Stirling engine creates a $.041 \mathrm{gha} / \mathrm{cap}(11 \%)$ reduction in the energy $\mathrm{EF}$ for new build. Using the electricity generated by the engine on site (combined heat and power) increases this reduction to .209gha/cap, which represents a raw savings of $55 \%$ over typical new build. 


\section{Water saving measures}

The REAP water interface provides a coefficient whereby water use levels can be evaluated against land take (in this case water use) and the embodied energy required for delivering water supplies.

In section 2.3.4. the draft SPG calls for:

Minimum: $100 \%$ inclusion of water saving devices.

Minimum: Residential developments to achieve average water use in new dwellings of less than $40 \mathrm{~m} 3$ per bedspace per year.

Preferred: Residential developments to achieve average water use in new dwellings of less than $25 \mathrm{~m} 3$ per bedspace per year.

Minimum: Rainwater harvesting for gardens where appropriate.

Preferred: Rainwater harvesting from $80 \%$ of roof area for landscaping and flushing toilets.

These standards have been combined and evaluated for this report as a decrease in water use levels to $40 \mathrm{~m} 3 /$ bedspace per year for new buildings, and then a further decrease to $25 \mathrm{~m} 3 /$ bedspace per year. Assuming an average bedspace of 2.7 per London house, these reductions equate to total household water use levels of $108 \mathrm{~m} 3$ and $67.5 \mathrm{~m} 3$. Current UK household water use levels are approximately $150 \mathrm{~L} /$ day, which equates to approximately $128 \mathrm{~m} 3$ per year, or $47 \mathrm{M} 3 /$ per bedspace/year for London. ${ }^{14}$ A table of water use and per-capita water consumption is provided below:

Table 11 Domestic water use by end use

\begin{tabular}{|c|c|c|}
\hline END USE & $\begin{array}{c}\text { VOLUME/ } \\
\text { USE (L) }\end{array}$ & $\begin{array}{c}\text { PER CAPITA } \\
\text { CONSUMPTION } \\
\text { (L/h/d) }\end{array}$ \\
\hline Toilet & 6 & 28 \\
\hline Shower & 45 & 25 \\
\hline Bath & 85 & 30 \\
\hline Taps (internal) & - & 12 \\
\hline Washing machine & 60 & 13 \\
\hline Dishwasher & 20 & 8 \\
\hline Garden & - & 6 \\
\hline TOTAL* & & $\mathbf{1 2 2}$ \\
\hline
\end{tabular}

Taken from EA, 2005 statistics.

* A further $20+\mathrm{L} /$ day are assumed to come from 'other' uses.

It is assumed that reductions to $40 \mathrm{~m} 3 /$ bedspace per year can be achieved through installation of low flush toilets in all new homes and water saving showerheads. Further reductions to $25 \mathrm{~m} 3 /$ bedspace per year are assumed to be created through rainwater collection systems and reuse of grey-water for non-potable purposes. The resulting EF savings for these reductions in water use are displayed in Figure 4.

${ }^{14}$ Calculated from EA 2005 statistics. 
Figure 4 EF savings: Water savings measures (Gha/cap)

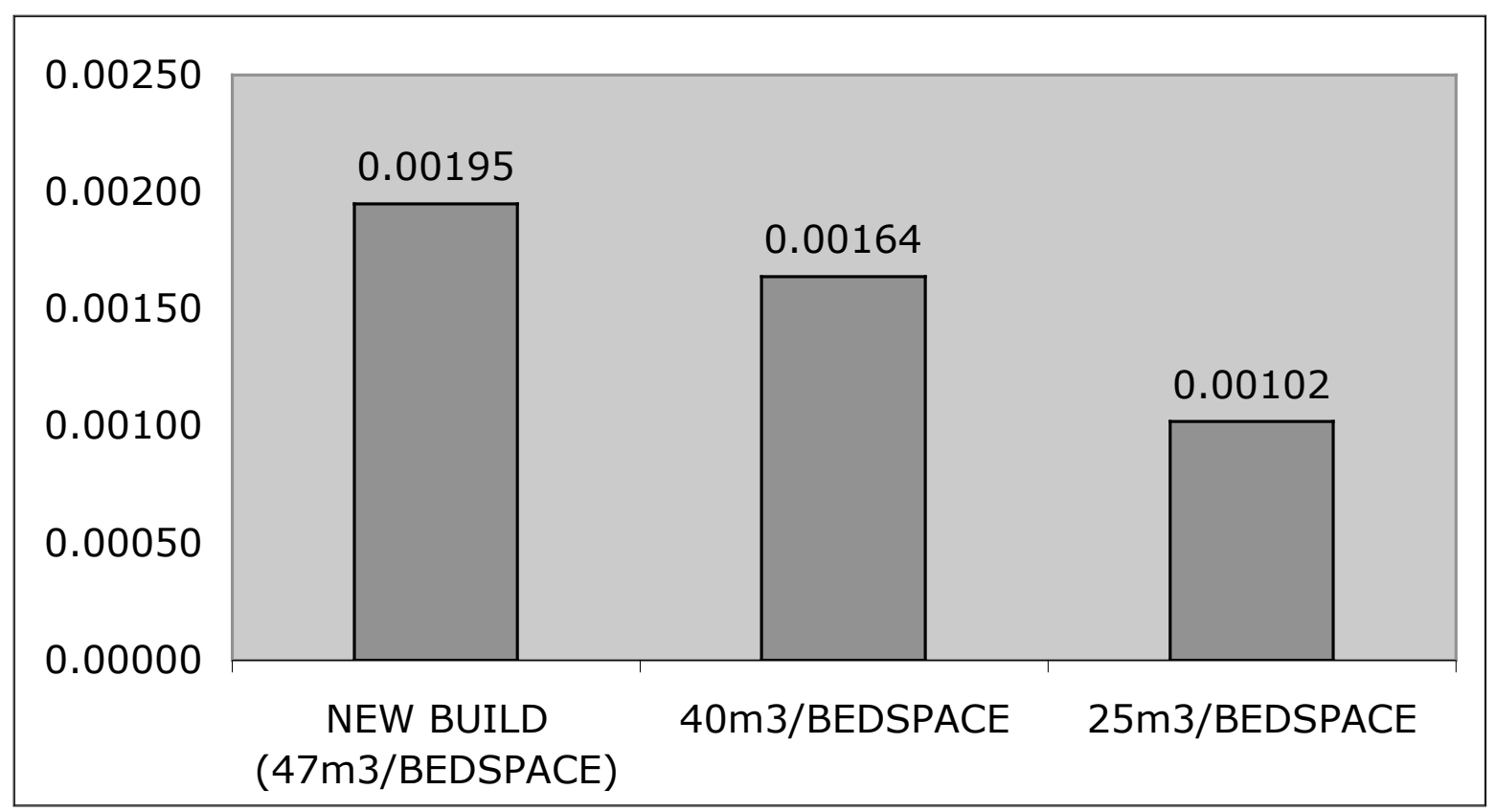

Decreasing water use to $40 \mathrm{~m} 3 /$ bedspace reduces the water EF for London new build to $.00016 \mathrm{gha} / \mathrm{cap}$ - a savings of about $15 \%$. Further decrease in water use to $25 \mathrm{~m} 3$ yields a water EF savings of $.00093 \mathrm{gha} / \mathrm{cap}$ (or about $47 \%$ ). Whilst relatively significant gains within the Footprint for domestic water use are achieved with the scenarios evaluated here, the impact of water saving efforts on the overall EF evaluated here is minimal. Savings such as these will have little effect on the overall Footprint of housing construction as evaluated in this paper. However, as with the evaluation of renewable resources, this conclusion also reflects back on the Ecological Footprinting approach itself and its inherent assumptions and weightings. 


\section{Recycling household waste}

The waste scenario was evaluated with the REAP waste scenario manager. The REAP waste scenario manager allows the user to adjust household and civic amenity waste and recycling levels. Footprint scores for waste are calculated based on energy and materials saved through recycling and a corresponding reduction in weight (and fuel use) for waste materials sent to landfill. Data on London waste were taken from comprehensive London Waste Action statistics (MEL 1999).

In section 2.7,2 the draft SPG calls for:

Minimum: Provide facilities to recycle or compost at least $25 \%$ of household waste by means of separated dedicated storage space. By 2010 this should rise to 35\%

Preferred: Provide facilities to recycle or compost at least $35 \%$ of household waste. By 2015 this should rise to $60 \%$

These standards have been evaluated as a $25-60 \%$ increase in recycled paper, glass, cans and card. ${ }^{15}$ Table 12 displays the typical waste values for these materials, and recycling volumes evaluated for each of the standards above.

Table 12 London household waste and recycling levels

\begin{tabular}{|c|c|c|c|c|}
\hline $\begin{array}{c}\text { PRIMARY } \\
\text { CATEGORY }\end{array}$ & $\begin{array}{c}\text { BASELINE WASTE } \\
\text { (KILOTONNES) }\end{array}$ & $\begin{array}{c}\mathbf{2 5 \%} \\
\text { RECYCLED }\end{array}$ & $\begin{array}{c}\mathbf{3 5 \%} \\
\text { RECYCLED }\end{array}$ & $\begin{array}{c}\mathbf{6 0 \%} \\
\text { RECYCLED }\end{array}$ \\
\hline Paper & 729 & 182 & 255 & 437 \\
\hline Glass & 257 & 64 & 90 & 154 \\
\hline Cans & 120 & 30 & 42 & 72 \\
\hline Card & 95 & 24 & 33 & 57 \\
\hline
\end{tabular}

Source: MEL Research 1999

For the purposes of these scenarios baseline recycling levels were set at ' 0 .' This of course creates a level of inflation in our findings given that current household recycling rates for materials such as paper and card are currently about $20 \%$ (BFF, 2002). However, it was decided to evaluate this parameter against a baseline situation in which no recycling facilities were provided, and in which no recycling took place. This better gauges the effect of planning standards aimed at providing facilities to encourage different levels of recycling in new development. ${ }^{16}$ The results of this analysis are displayed in Figure 6 below.

\footnotetext{
15 There was no interface for plastic recycling included in the REAP waste scenario manager. However, as only $.15 \%$ of all plastic used in London by all consumers (not just households) is recycled (BFF 2002), the omission of this data is likely to have no effect on this analyses.

16 A comparison of EF changes between 25 and $35 \%$ and 25 and $60 \%$ recycling levels will provide a rough estimate of the impact of increased recycling rates from current levels.
} 
Figure 5 EF savings: Recycling household waste (Gha/cap)

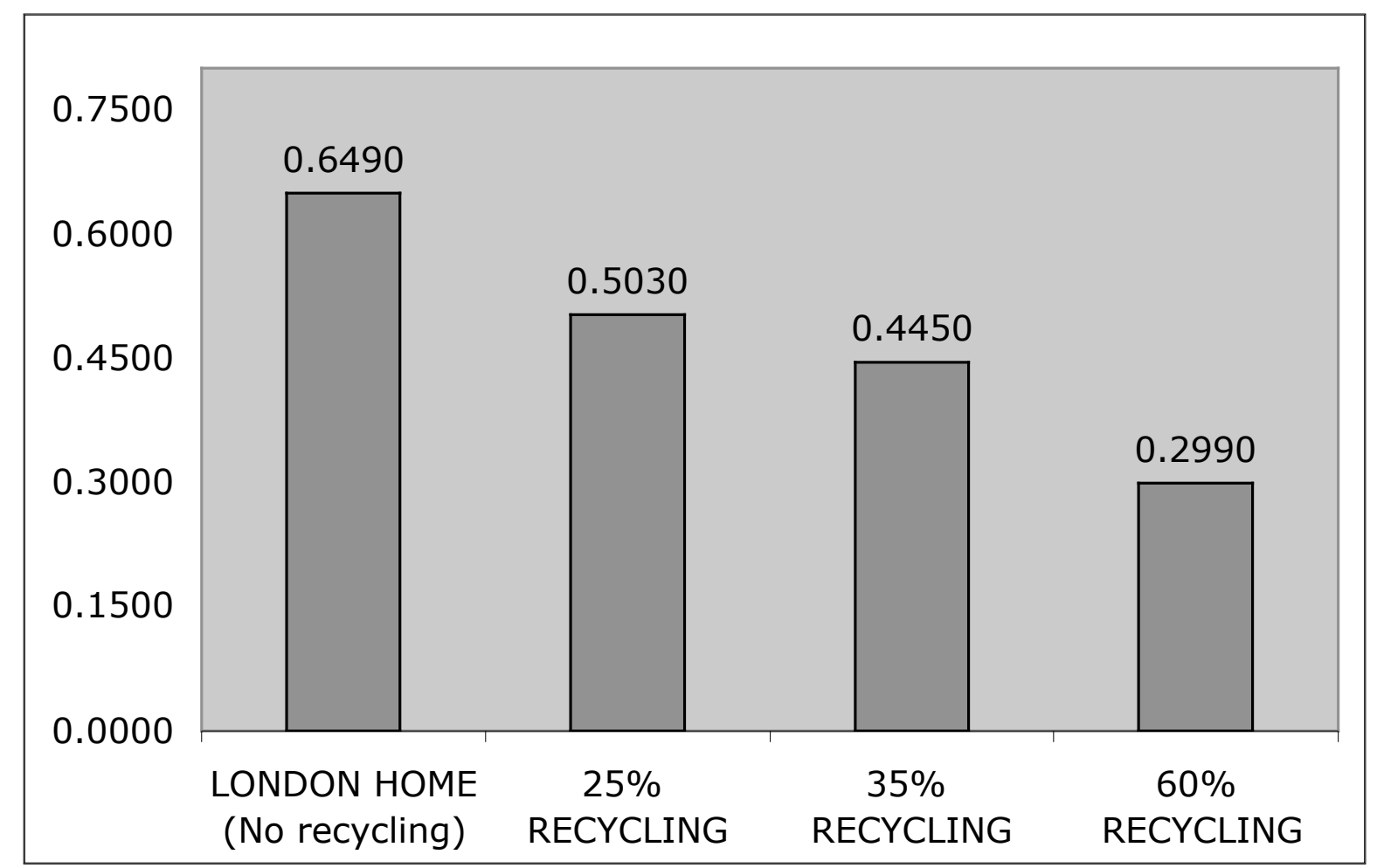

It appears that recycling household waste can have a significant effect on the waste EF for a typical London home. Recycling $25 \%$ of card, cans, glass, and paper leads to a $.156 \mathrm{gha} / \mathrm{cap}$ waste EF reduction over no recycling at all. Increasing these levels more ambitiously, to $60 \%$ yields a $.35 \mathrm{gha} /$ cap savings over non-recycled waste. As mentioned previously, current household recycling levels are closer to $20 \%$ for some materials. However, our findings demonstrate that significant waste EF reductions can still be achieved beyond levels of current practice with incremental increases in recycling rates. 


\section{Aggregated scenario results}

A summary of the standards evaluated in this research, EF scores for those standards, and resulting savings is presented in Table 13 below. Larger savings from preferred standards are displayed where applicable.

Table 13 Evaluated standards and EF savings

\begin{tabular}{|c|c|c|c|}
\hline EVALUATED STANDARD & $\begin{array}{c}\text { EF } \\
\text { SAVINGS } \\
\text { (GHA/CAP) }\end{array}$ & $\begin{array}{c}\text { \% SAVINGS } \\
\text { (BASELINE) }\end{array}$ & $\begin{array}{c}\text { \% TOTAL } \\
\text { SAVINGS }\end{array}$ \\
\hline Use of recycled materials & 0.0123 & 1.07 & 2.02 \\
\hline Avoiding high embodied energy materials & -0.0030 & -0.26 & -0.49 \\
\hline Community heating & 0.0410 & 3.57 & 6.72 \\
\hline Combined heat and power & 0.2090 & 18.19 & 34.25 \\
\hline Water savings measures & 0.0010 & 0.09 & 0.16 \\
\hline Recycling household waste & 0.3500 & 30.46 & 57.35 \\
\hline TOTAL & $\mathbf{0 . 6 1 0 3}$ & $\mathbf{5 3 . 1 2}$ & $\mathbf{1 0 0 . 0 0}$ \\
\hline
\end{tabular}

Figure 6 presents the percentage of total savings for each of the standards evaluated in this report.

\section{Figure 6 Evaluated standards and EF savings (Percent total EF savings)}

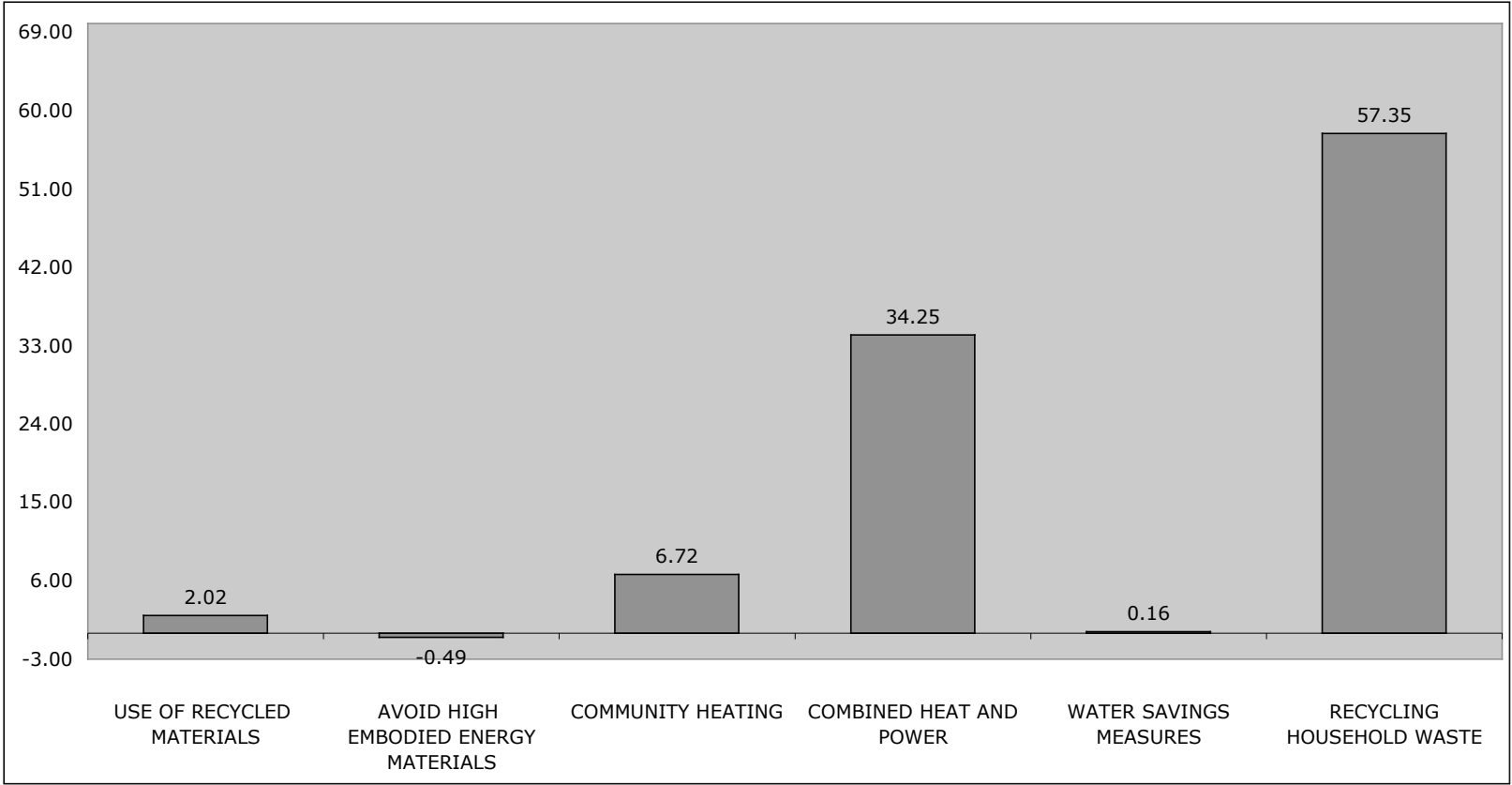

With regard to Figure 6 and Table 13 several broad conclusions can be made. The overall EF reduction found in our scenarios is .6103 . This represents an approximate $50 \%$ reduction in the 'business as usual' aggregate EF score for the components evaluated here. Putting these 
figures into a wider perspective, an EF reduction of .6103 represents an approximate 10\% decrease on the total Footprint of the average Londoner (BFF 2002, WSP, 2003).

\section{A tool for prioritising action?}

The data in Figure 6 and Table 13 clearly demonstrate that in order to have the greatest overall impact, the standards evaluated here should be implemented as a package of measures. Like the concept of sustainability itself, sustainable housing construction and planning is a multi-dimensional process, with several components adding to a sustainable whole. Nevertheless, situations will arise in planning and development in which it is necessary to make choices between standards and to set priorities for action in certain areas. Our data clearly indicate that some standards are more effective than others at reducing the London Footprint. The component-based analysis that is presented in this paper can offer planners and developers some guidelines for decisions between design options, provided that the limitations of this Footprinting approach are also accounted for.

Looking back at Figure 6, we find that roughly $90 \%$ of the overall reduction comes from the recycling and combined heat and power measures. The largest EF reduction comes from reducing household waste $(0.35 \mathrm{gha} / \mathrm{cap})$, which represents about $58 \%$ of the combined EF reductions for all evaluated standards. The inclusion of combined heat and power in large developments contributes a further $34 \%$ of the total reductions in our scenarios. Findings such as these seem to offer a relatively straightforward suggestion that recycling and CHP should be priorities for planners concerned with sustainable housing. Conversely, the analysis presented here suggests at first sight that less emphasis should be placed on the use of recycled or lower embodied energy materials, or water measures, because these have little impact (and indeed a potentially negative impact in the case of avoiding high embodied energy materials) on the infrastructure EF of a new home.

The accessibility of the aggregate EF metaphor does make for easy comparisons between different policy measures, as illustrated in the preceding discussion. It is easy to add and subtract EF scores or to calculate relative savings compared to other measures or the savings as a whole. Nevertheless, such accessibility and the ease of comparison can come at the cost of over-aggregation, which in turn leads to conclusions that are somewhat facile, and perhaps even dangerously misleading in planning situations. Therefore, results such as these need to be understood and interpreted in terms of the strengths and weaknesses of the EF approach. The real impact of a particular planning standard is not necessarily commensurate with land, energy, and transport 'take.' This means that reliably and accurately comparing policy standards is more difficult than it appears. A discussion of the strengths and weaknesses of the REAP programme as a planning tool (with specific regard to the findings in this report) concludes this paper.

\section{Strengths and weaknesses of REAP as a planning tool}

\section{A detailed analysis}

This application of REAP demonstrates one of the great strengths of the tool in terms of planning policy development; that is, the ability to conduct detailed analyses of the environmental impact of following certain policy paths. A variety of possible scenarios can readily be subjected to evaluation, allowing the policy-maker to pursue a 'what if' approach to policy development. Furthermore, the interactive nature of the tool allows the analyst to tailor many parameters to fit with local circumstances (subject to data availability - see 
below) in a flexible way. It is the case that building any specific scenario requires a number of assumptions to be made and that the results may well be sensitive to some of these assumptions. But the very process of building scenarios and identifying assumptions requires the policy-maker to be specific about the content of policies and their implications in a transparent way. This in itself is a contribution to policy development, quite apart from the debates and discussions that would follow on from the results of the evaluation.

\section{Holistic comparisons}

Another strength of the REAP tool, and the component-based Footprinting approach behind it, is that it takes into account the "mutual interrelationships between economic sectors" (Wiedmann and Barrett, 2005:5), or, in this case, between the different EF components of a new house. In this sense, it allows for the production of more inclusive 'what if' scenarios. A good example of this strength can be found in the output from the materials scenario avoiding high-embodied energy materials. Because REAP takes into account the energy used in transporting materials, as well as in creating them, we were able to show that substituting timber for aluminium in new houses may actually increase the EF for a house. Whilst this specific finding does ignore differences in supply for these two resources (as will be discussed below) and may be sensitive to the national transport data used, it also demonstrates the importance of taking a more holistic focus on the sustainability of a particular building practice. Focusing only on one EF component, such as the embodied energy of materials, without accounting for the transport of those materials could lead to relative policy priorities that are inherently unsustainable when the effects of other EF factors, such as transport, are taken into account.

Additionally, it is important to account for the effects of particular EF components across other consumption categories. Although it is not analysed in the scenarios presented in this paper, changing the materials composition of a house can have a dramatic effect on the energy use patterns of housing residents. Whereas the materials used to create a house have a relatively small impact on the overall EF of a UK house (as evidenced in Table 2), the effect of mandating higher insulation standards in the 2000 Building Regulations (see ODPM, 2000) has been to reduce the typical energy use of a 'new 2000 ' house by roughly $40 \%$, as compared to a 'stock' or pre-2000 house (Wiedmann et al. 2003). The component-based model in REAP allows for the immediate, within-component effects of adjusted parameters to be compared to knock-on effects across other consumption categories. This ability may significantly reduce the complexity of planning decisions for sustainability.

\section{Constraints of scope}

Despite the advantages of the component EF method in highlighting the interrelated nature of the energy-use and land-take relationships within Footprint components or between consumption categories, there remains "considerable controversy on the issue of whether ecological footprints can and should be used as a tool for measuring sustainability, or merely as a tool for visualising human impact in relation to the earth's carrying capacity" (Moffatt et al 2001: 31). It is important to recognise that the range of relationships included within a footprint evaluation are necessarily limited. An EF score is a land-based metaphor for the energy and resources required to produce and transport consumer products, and the area of 'assimilative' land required to absorb the impacts of production, transport and waste. Although comprehensive in a resource-based sense, it is necessarily not holistic in its approach to measuring sustainability. It would be inaccurate and misleading to define a 
planning practice or standard as sustainable on the basis of a component EF score alone. As recognised by its creators, it does not produce a dynamic picture of changing conditions (Wackernagel and Rees 1996), nor does it say anything about quality of life (Chambers et al., 2000). It is the former shortcoming that is particularly pertinent in this case.

Sustainability as a concept is predicated on the principles of futurity and fairness; resource stocks should be conserved so that they are available to future generations. The EF score misses this relationship on two counts. Firstly, it does not address the security or 'futurity' of specific resources, although it does present a metaphor for the extent to which global resource capacities are being exceeded. Thus, it is difficult to account for the desirability of using renewable resources or energy sources. With reference to the preceding discussion, the renewable nature of timber is not factored into the comparison of the costs and benefits of switching from aluminium to timber-based building products. This would seem to be a significant omission in terms of what is defined or evaluated as sustainable resource use.

Secondly, aggregating EF scores on a global scale means that regional and local differences in resource levels are not accounted for. A discussion of the water-use scenario results illustrates this point. Water savings measures, although representing a fairly dynamic EF category in which large relative gains can be made, do not significantly contribute to the overall EF reductions presented in this paper. These findings would seem to suggest that water conservation should not be a priority for planners aiming at sustainability. However, the security of water supply, particularly in the London context, is an important thematic priority for sustainable housing, as evidenced by its emphasis in the London Plan, the draft SPG which informs this report, and other planning guidance (see for instance DTI, 2004). A component-based EF analysis of consumption and resource use (as opposed to supply) is ill equipped to evaluate such issues, and does not provide a reliable indication of sustainability.

\section{Data issues}

The major inhibitor for the accuracy of any Footprinting exercise is the quality of the data used to produce it. National-level resource flow accounts are simply too broad to make accurate comparisons of the sustainability of different policy options, particularly when transport- levels are included as part of the equation. Although the environmental extended input output analysis used by REAP makes it theoretically possible for the level of analysis to be taken down to the level of the individual consumer (Wiedmann and Barrett, 2005), our experience indicates that such micro-scale evaluation is practically impossible given current data constraints. Local level data is often proprietary, or, more commonly, does not exist. Where more specialised data is available, it may not be easily compatible with the REAP interface. There is a certain amount of path dependence in what is achievable with REAP analysis, due to the way that the input-output models are structured, and the data-input categories included with the programme. For instance, in our research, local-level data on waste and recycling levels did not match the input component for waste in the REAP waste scenario manager. As such, the data had to be disaggregated into REAP-friendly components for evaluation. This makes the data less internally reliable, and decreases the external validity of the REAP output for comparison with existing local data-sets.

\section{Conclusions}

The paper has presented an assessment of an important new Ecological Footprinting tool in the context of local planning policy for more sustainable housing construction in London. It has demonstrated that the REAP tool has considerable potential in terms of policy 
development. Once the preliminary work has been undertaken, it is possible to explore a variety of "what if" scenarios linking the details of policy and strategy statements to potential environmental impact. This can be an aide in the fine-tuning of strategy, in making judgement about policy priorities and in assessing policy directions. Compared to other sustainability assessment methods, REAP has advantages in terms of the detail of its analysis, the flexibility with which it can be applied and the transparency of its calculations. As such, it could be a significant contribution to policy learning within policy bodies.

However, this conclusion needs to be seen in the context of an understanding that such Ecological Footprinting provides only a partial picture of environmental sustainability, let alone sustainable development as a whole. There are also important issues concerning data availability and assumptions that need to be taken into account when using the results of such an analysis. One implication is that a sensitivity analysis would probably be an appropriate accompaniment to any use of such Ecological Footprinting to shape policy developments. Another conclusion that may be drawn is the such Footprinting can be an important element of a suite of policy tools, which as a package draw attention to the range of sustainability impacts associated with implementing a specific policy strategy. These qualifications should not though distract from the overall conclusion that such Footprinting can assist in thinking policy implementation through in detail and thus inform strategy development. 


\section{References}

AggRegain, 2006, “Sustainable Aggregates” http://www.aggregain.org

Barrett J, 2001, "Component Ecological Footprint: Developing sustainable scenarios" Impact Assessment and Appraisal 19(2) 107-118

Barrett J, Wiedmann T, Ravetz J, 2004, "Development of Physical Accounts for the UK and Evaluating Policy Scenarios", Ecological Budget UK Report No. 1, Resources and Energy Analysis Programme, Stockholm Environment Institute, York and Centre for Urban and Regional Ecology, Manchester, http://www.ecologicalbudget.org.uk

Best Foot Forward (BFF), 2002, "City Limits: A Resource Flow and Ecological Footprint Analysis for Greater London”, IWM (EB), London

Carbon Trust, 2005, “Community Heating for Planners and Developers”, EST, London

Combined Heat and Power Association, 2005, "Time to Take a Fresh Look at CHP" http://www.chpa.co.uk/news_downloads/2005/Time\%20to\%20Take\%20a\%20Fresh\%20Loo $\mathrm{k} \% 20 \mathrm{at} \% 20 \mathrm{CHP} \% 20$ October\%202005.pdf

DFT, 2002, "Revised National Travel Survey Data for Urban and Rural Areas" http://www.dft.gov.uk/stellent/groups/dft_transstats/documents/page/dft_transstats_507680.p df

DTI, 2003, "Domestic energy consumption by end use, 1970 to 2003," http://www.dti.gov.uk/energy/statistics/publications/ energy-consumption/domestictables/page18071.html

DTI, 2004, "Better Buildings,- Better Lives: Sustainable Buildings Task Group Report", Department of Trade and Industry (DTI), London

DTI, 2005a, "Energy - its impact on the Environment and Society: Annex 3B Regional and Local use of Energy in the Domestic Sector", Department of Trade and Industry (DTI), London

DTI, 2005b, "Energy Trends March, 2005"

http://www.dti.gov.uk/energy/inform/energy_trends/mar_05.pdf.

EA, 2005. "Sustainable Homes the Financial and Environmental Benefits", The Environment Agency, pubished by The Stationery Office, London

GFN, 2004, "National Footprint and Bio-capacity Accounts" http://www.Footprintnetwork.org/gfn_sub.php?content=national_Footprints.

GLA, 2004, "The London Plan: Spatial Development Strategy for London." http://www.london.gov.uk/mayor/strategies/sds/index.jsp

GLA, 2005a, "2004 London's Housing Capacity Study" http://www.london.gov.uk/mayor/planning/capacity_study/index.jsp 
GLA, 2005b, "Sustainable Design and Construction. The London Plan (Spatial

Development Strategy for London). Draft Supplementary Planning Guidance", Greater London Authority (GLA), London

Haraldsson H, Ranhagen U, Sverdrup H, 2001, "Is Eco-living More Sustainable than Conventional Living? Comparing Sustainability Performances between Two Townships in Southern Sweden" Journal of Environmental Planning and Management 44:5 663-679

Holden E, 2004, "Ecological Footprints and Sustainable Urban Form" Journal of Housing and the Built Environment 19:1 91-109

McGregor PG, Swales JK, Turner KR, 2004 "The impact of Scottish consumption on the local environment: an alternative to the Ecological Footprint?" Quarterly Economic

Commentary 29 29-34

MEL Research, 1999, "Towards a Waste Reduction Plan for London" http://www.londonwasteaction.org/archive.html

Miller R, Blair P, 1985, “Input-output Analysis: Foundations and extensions” (PrenticeHall, New Jersey)

Moffatt I, 2000. "Ecological Footprints and Sustainable Development" Ecological Economics 32 359-362

Moffat I, Hanley N, Allen S, Fundingsland M, 2001. Sustainable Prosperity: Measuring Resource Efficiency, DETR, 2001.

Moffat I, Wiedmann T, and Barrett J, 2005 "The impact of Scotland's economy on the environment: a note on input-output and Ecological Footprint analysis" Quarterly Economic Commentary $3037-44$

Nye M, Rydin Y, 2006 "Evaluating sustainable housing construction standards in London: report to the Greater London Authority" LSE SusCon Project, Centre for Environmental Policy and Governance, London School of Economics, London

Ravetz J, Barrett J, Paul A, 2006 "Counting consumption, West Midlands - CO2 emissions, material flows and Ecological Footprint of the West Midlands" WWF-UK, Godalming, Surrey http://www.ecological budget.org.uk

Rees W, 1998 “How Should a Parasite Value its Host?” Ecological Economics. 25 49-52

Rees W, 2000 "Eco-Footprint Analysis: Merits and Brickbats." Ecological Economics. 32 371-374

Smith R, Kersey J, Griffiths P, 2002, "The Construction Industry Mass Balance: Resource Uses, Wastes and Emissions" Viridis Report, VR4, Viridis, London

Wackernagel M, Rees W, 1996, Our Ecological Footprint: Reducing human impact on the earth. (New Society Publishers, Canada)

Wackernagel M, Monfrada C, Moran D, Wermer P, Goldfinger S, Deumling D, Murray M, 2005. "National Footprint and Biocapacity Accounts 2005: The underlying calculation method" Oakland: Global Footprint Network, http://www.globalfootprint.org 
Wiedmann T, Barrett J, Cherrett N, 2003, "Sustainability Rating for Homes - The Ecological Footprint Component” York, Stokholm Environment Institute

Wiedmann T, Barrett J, 2005, "The Use of Input-Output Analysis in REAP to Allocate Ecological Footprints and Material Flows to Final Consumption Categories", Ecological Budget UK Report No. 2, Resources and Energy Analysis Programme, Stockholm Environment Institute, York, http://www.ecologicalbudget.org.uk

Wiedmann T, Minx J, Barrett J, Wackernagel M, 2006, “Allocating Ecological Footprints to final consumption categories with input-output analysis" Ecological Economics 56:1 28-48.

WSP Environmental Ltd and Natural Strategies LLC, 2003, “Towards a Sustainable London: Reducing the Capital's Ecological Footprint. Phase 1 Report: Determining London's Ecological Footprint and Priority Impact Areas for Action", London Remade/London First, London

WWF-UK, 2004, "Living Planet Report, 2004”, World Wildlife Fund (WWF-UK), Surrey

WWF-UK, 2005a, "Regional Footprints: Solutions to Reduce our Global Impact", World Wildlife Fund (WWF-UK), Surrey

WWF-UK 2005, "Reducing Wales' Ecological Footprint: A Resource Accounting Tool for Sustainable Consumption”, World Wildlife Fund (WWF-Cymru(, Cardiff 